\title{
A PEDAGOGIA DO CORPO OPRIMIDO COMO VIA PARA ALFABETIZAÇÃO CORPORAL DA CRIANÇA
}

\author{
PEDAGOGÍA DEL CUERPO OPRIMIDO COMO FORMA DE ALFABETIZACIÓN DEL \\ CUERPO DEL NIÑO
}

PEDAGOGY OF THE OPPRESSED BODY AS A WAY TO CHILD'S BODY LITERACY

Mesaque Silva CORREIA ${ }^{1}$

RESUMO: O pensamento pedagógico freiriano tem favorecido significativamente a ampliação de práticas educativas formais e não formais, e contribuído com a ampliação de leituras críticas de mundo no qual os educadores têm buscado em sua base epistemológica amparo para suas inquietudes. Desta forma, partindo das leituras do legado freiriano, o objetivo do presente estudo é de conjecturar possibilidades, e não uma regra a ser seguida, de ancoragem do ensino da Educação Física no contexto da Educação Infantil nos princípios teóricos e metodológicos daquela que aqui chamarei de "Pedagogia do Corpo Oprimido". Para tanto, apresenta-se e reflete-se sobre os princípios norteadores de tal proposta, a fim de contribuir para o debate no campo da Educação e, especialmente, da Educação Física em torno da importância de compreender a criança como ser existencialmente corporal que, como tal, não aprende e nem se conscientiza apenas com a mente.

PALAVRAS-CHAVE: Educação física. Educação infantil. Alfabetização corporal. Pedagogia freiriana.

RESUMEN: El pensamiento pedagógico de Freirean ha favorecido significativamente la expansión de las prácticas educativas formales y no formales, y ha contribuido a la expansión de las lecturas críticas del mundo en el que los educadores han buscado en su base epistemológica apoyo a sus preocupaciones. Así, partiendo de las lecturas del legado freirean, el objetivo de este estudio es conjeturar posibilidades y no una regla a seguir, anclando la enseñanza de la Educación Física en el contexto de la Educación Infantil Temprana en los principios teóricos y metodológicos de la "Pedagogía del Cuerpo Oprimido". Con este fin, presenta y reflexiona sobre los principios rectores de esta propuesta, con el fin de contribuir al debate en el campo de la Educación y la Educación Física en torno a la importancia de entender al niño como existencialmente corporal y como tal no aprende ni se da cuenta sólo con la mente

PALABRAS CLAVE: Educación física. Educación en la primera infancia. Alfabetización corporal. Pedagogía Freirean.

${ }^{1}$ Universidade Federal do Piauí (UFPI), Teresina - PI - Brasil. Professor no Departamento de Método e Técnicas de Ensino (DMTE). Doutorado em Educação Física (USJT). ORCID: https://orcid.org/0000-0002-0258-7111. Email: mesaquesilvacorreia@ufpi.edu.br

RPGE- Revista on line de Política e Gestão Educacional, Araraquara, v. 24, n. 3, p. 1559-1572, set./dez. 2020. e-ISSN:1519-9029 
ABSTRACT: Freire's pedagogical thinking has significantly favored the expansion of formal and non-formal educational practices, and has contributed to the expansion of critical readings of the world in which educators have sought in their epistemological base support for their concerns. Thus, starting from the readings of the Freirean legacy, the objective of the present study is to conjecture possibilities, and not a rule to be followed, to anchor Physical Education teaching in the context of Early Childhood Education in the theoretical and methodological principles of "Pedagogy of the Oppressed Body. To this end, it presents and reflects on the guiding principles of such a proposal, in order to contribute to the debate in the field of Education and Physical Education around the importance of understanding the child as an existentially corporal being and as such does not learn and nor gain awareness with the mind alone.

KEYWORDS: Physical Education. Child education. Body literacy. Freirean pedagogy.

\section{Introdução}

Eu havia terminado uma palestra sobre "a ideologia de Paulo Freire e seu uso na área da Educação Física" para alunos do curso de Educação Física de uma universidade da cidade de São Paulo. Já tinha entrado naquele estado de letargia que vem depois de um grande esforço intelectual, em que não queremos mais pensar em nada muito inteligente, quando uma professora veio me dizer que havia dispensado o carro da universidade, o qual que me levaria ao aeroporto, e que ela mesma se encarregaria disso, pois queria ter uma conversa comigo no caminho.

É preciso dizer que o translado para o aeroporto se dava imediatamente após o almoço em que eu havia tomado, pelo menos, uma cerveja. Não se podia dizer que eu estivesse exatamente num estado de alerta intelectual. Ela não gastou muito tempo em amenidades introdutórias, entrando diretamente no assunto e me fez a grande pergunta: "Professor, eu queria pedir para que o senhor falasse um pouco sobre a situação da Educação Física na Educação Infantil. Gostaria de saber se o que é trabalhado nas aulas de Educação Física vem de encontro com as necessidades de nossas crianças. Em quais princípios teóricos as práticas corporais podem ser sustentados?”.

Até aquele momento, para falar a verdade, eu nunca tinha me preocupado especificamente com a questão do ensino da Educação Física na Educação Infantil. Desconfio que minha suposta autoridade para falar sobre a questão se devia ao fato de ter publicado alguns textos sobre a temática da "didática da Educação Física".

Mais tarde, bem mais tarde, dei uma carona para um aluno e, no conturbado trânsito da capital teresinense, perguntou-me se eu achava que "um dos grandes desafios da Educação Física na Educação Infantil era ensinar as destrezas motoras para além dos gestos 
padronizados". No afã do momento respondi: "Eu penso que um dos grandes desafios da modernidade é responder perguntas profundas dentro de carros em trânsitos conturbados".

Talvez esteja ali, naquelas constrangedoras situações, a origem desse texto. Não seria confortável e confortador ter à mão uma definição rápida para sacar em situações como esta? Munido de definições expressas para, digamos, uma centena de explicações que hoje encontram postas no campo teórico da Educação Física, eu quase poderia ter a certeza que nunca mais seria pego desprevenido.

Mas é claro que, após ter gasto um pouco do meu tempo e esforço em busca de respostas, que abram-se aspas "ainda encontro-me à procura", acredito que sua utilidade vai um pouco além daquela de salvar um professor em apuros dentro de carros em trânsitos conturbados. Fazer parte de um determinado campo intelectual significa, sobretudo, dominar sua epistemologia, isto é, os termos, as palavras, os conceitos, em suma, seu discurso. No caso da Educação Física, este discurso é, hoje, amplo e diverso. Acho que já passamos, há muito, daquela fase de ficarmos, indefinidamente, discutindo o que é Educação Física, para quê e a quem serve.

O campo intelectual da Educação Física é, hoje, um campo de Propostas. Assim mesmo, com (P) maiúsculo, em virtude das inúmeras possibilidades apresentadas por sua comunidade científica. Entretanto, um dos grandes desafios da Educação Física Escolar está em organizar e sistematizar os conteúdos a serem trabalhados ao longo da vida escolar, da Educação Infantil até o Ensino Médio. Há diversas bibliografias sobre esse tema em forma de livros, artigos, além de propostas curriculares organizadas em nível nacional, estadual e municipal: Le Bouch (1981); Freire (2011); Betti (1991); Coletivo De Autores (1992); Kunz (1991-1994); Daólio (1995); Brotto (1995); Neira (2001); Moreira (2009); Moreira; Nista-Piccolo (2009); Awad (2010); Moreira; Pereira (2011); Correia (2020); Nista-Piccolo; Go Tani (2014); Parâmetros Curriculares Nacionais - PCNs (1997); Base Nacional Comum Curricular - (2017), as quais têm como objetivo orientar os professores de Educação Física no decorrer de suas ações educativas. No entanto, por necessitarem de exemplificações claras e objetivas de como sistematizar os conteúdos ao longo da vida escolar, quase sempre ficam muito mais no plano retórico do que na sua efetivação na quadra de aula.

Correia (2020) descreve que as propostas curriculares da Educação Física desenvolvidas ao longo do século XX e início do século XXI, que buscaram superar a educação tradicional na área da Educação Física, até o presente momento, pouco conseguiram alterar nas práticas realizadas. Ao discutir sobre essa questão Correia; Miranda e Velardi (2011), apontam que não é raro na área da Educação Física observamos educadores escondendo-se em aulas que se 
constituem em verdadeiros rituais a serem seguidos, desenvolvidas através de uma educação diretivista, para não revelarem o medo que têm de problematizar e dialogar sobre as práticas corporais. Para tal, justificam que "problematizar" e "dialogar" são perdas de tempo, fazendo adormecer a sua capacidade crítica e, consequentemente, a do educando.

Por essa razão, acredita-se que o grande desafio do ensino da Educação Física na escola, centra-se na necessidade de compreensão de que as práticas corporais são manifestações culturais oriundas do mundo da vida (sejam elas as danças, as ginásticas, atividades rítmicas, os esportes, os jogos e as brincadeiras). Desse modo, a educação do corpo deve caminhar na contramão do imobilismo do pensar, da reprodução do movimento e da disciplina do corpo. Deve preocupa-se em refletir sobre o movimento humano de forma dinâmica e contextualizada (CORREIA; MARQUES; MIRANDA, 2019).

Por esse motivo, no decorrer desse estudo ensaístico conjecturam-se possibilidades e não uma regra a ser seguida; de ancorarmos no desenvolvimento do ensino da Educação Física no contexto da Educação Infantil, nos princípios teóricos e metodológicos da "Pedagogia do Corpo Oprimido". Trata-se de uma possibilidade de trabalho comprometida com a democracia, com a autonomia, com a cidadania e com o trabalho coletivo, com os quais a criança é compreendida em sua totalidade.

Assim sendo, faz-se necessário esclarecer que quando tomamos os princípios teóricos e metodológicos da "Pedagogia do Corpo Oprimido" como alicerce para o desenvolvimento de práticas corporais no contexto da Educação Infantil, a alfabetização corporal da criança passa a ser o objetivo primeiro de nossa intervenção; assim, o corpo é tomado como elemento norteador da proposta e a ideologia educacional de Paulo Freire seria a base teórica dessa pedagogia.

E para justificar os argumentos que me autorizam a realizar tal proposta, apoio-me numa frase de Freire (1989, p. 56) que pertence ao rol do conhecimento popular: "Não há saber mais ou saber menos. Há saberes diferentes". Num mundo de permanente produção de conhecimento proponho mais uma forma de saber e intervir a Educação Física Escolar, em especial no que se refere a alfabetização corporal da criança.

\section{A Educação Física no contexto da Educação Infantil como lugar de fala da alfabetização corporal da criança}

A inserção da Educação Física na Educação Infantil no Brasil vem se consolidando e ampliando desde a publicação da Lei de Diretrizes e Bases da Educação Nacional - LDB (Lei 
n 9.394/96), que propugna a Educação Infantil como primeira etapa da Educação Básica e a Educação Física como componente curricular desse nível de ensino, sobre o qual instituiu-se que: “A Educação Física integrada à proposta pedagógica da escola, é componente curricular da Educação Básica, ajustando-se às faixas etárias e às condições da produção escolar, sendo facultativa nos cursos noturnos" (LDB, Art.26, § $3^{\circ}$.).

Não obstante, a partir dessa Lei, a luta passou a ser pela universalização em território brasileiro da Educação Física nos currículos das creches e pré-escolas. Isso porque, apesar da legislação educacional brasileira determinar a obrigatoriedade da Educação Física na Educação Infantil, não está definido quem deve atuar com esse componente curricular (SAYÃO, 1999; SASEI, 2008; NISTA-PICCOLO; MOREIRA, 2012; SILVA; CARVALHO; CORREIA 2020). O trabalho com a linguagem, expressão corporal, jogos e brincadeiras na maioria dos sistemas de ensino, acaba ficando sobre responsabilidade do professor polivalente com formação em Pedagogia. Contudo, quase sempre falta a esse profissional à vivência de experiências corporais lúdicas através das brincadeiras e dos jogos, para completar a sua ação pedagógica com as crianças (SAYÃO, 2002).

Todavia, no ano de 2013 a Comissão de Educação, Cultura e Esporte (CE) aprovou o projeto de lei que torna obrigatório que o ensino de Educação Física, em todas as etapas da Educação Básica, seja conduzido exclusivamente por professores licenciados na área da Educação Física. Com origem na Câmara dos Deputados, o Projeto de Lei Complementar 116/2013 sugere prazo de cinco anos, a partir da vigência da lei, para que estados e municípios implantem a medida. Para o relator do projeto, a adoção da exigência do profissional de Educação Física para as séries iniciais é justificável em razão da relevância da formação motora na primeira infância (zero a seis anos) e da necessidade de o processo ser conduzido por profissionais com qualificação específica.

Importante dizer, também, que no interior da área da Educação Física, as lutas históricas, no sentido de inserir a Educação Física no contexto da Educação Infantil, vêm privilegiando o caráter da institucionalização ou da legalidade em detrimento da construção, da consolidação de elaborações teórico-práticas que a justifiquem pedagogicamente (SILVA; CARVALHO; CORREIA, 2020).

Considero um avanço para o Ensino da Educação Física o ajuste no currículo da Educação Infantil. Por outro lado, estou convencido que a concretização de uma educação pública de qualidade, da qual a Educação Física é parte integrante, não depende exclusivamente de leis, mas também, e fundamentalmente, de políticas e ações governamentais que garantam as condições objetivas de concretização. 
Num puro parêntese, não posso deixar de, no momento em que menciono a importância de políticas e ações governamentais que garantam as condições objetivas de implementação da Educação Física na Educação Infantil no sistema público de ensino, referendar que estados como: Espírito Santo; Mato Grosso do Sul e Piauí que, por meio de ações governamentais, iniciaram o processo de implementação da Educação Física na Educação Infantil. É mister salientar que, especificamente no Estado do Piauí, a câmara municipal, ancorada na LDB de 1996, estabeleceu, via projeto de lei $\mathrm{n}^{0} 84 / 17$, a inserção dos professores especialistas em Educação Física nos currículos da Educação Infantil, por entender a importância desse profissional na organização curricular da educação da criança, para a sua formação física, cognitiva, psíquica, social e humana.

Contudo, a organização curricular da Educação Física na Educação Infantil tem se demonstrado uma questão extremamente complexa que necessita contemplar, de um lado, as hierarquizações presentes entre os(as) profissionais da educação, as quais geram disputas por espaços político-pedagógicos e, de outro, os riscos de uma abordagem fragmentária de conhecimento que tende a compartimentar a criança (AYOUB, 2001).

Nas esteiras do pensamento de Sayão (2002), a ação pedagógica na Educação Infantil, ao longo da história, tem se constituído em uma perspectiva maturacional, na qual as crianças são concebidas como sujeitos universais e sobre elas incidem ações pedagógicas pautadas em princípios imutáveis de desenvolvimento. No meu modo de entender, a infância é ameaçada quando os professores que atuam nas creches e pré-escolas enfatizam apenas um modo de ser criança, deixando de fora a totalidade da infância. Por outro lado, a repetição de gestos padronizados, a ausência de atividades provocadoras da curiosidade e a fragmentação dos movimentos corporais, por meio de atividades pré-estabelecidas pelo professor, impossibilitam a criança de pensar por si.

Resende $(2015$, p. 8) critica a forma como as ações pedagógicas no contexto da Educação Infantil, em sua grande maioria, moldam a criança. De acordo com o autor, as práticas corporais no contexto da Educação Infantil, na maioria das vezes, robotizam as crianças, controlam corpos e regulam comportamentos. Afirma ele: “[...] as atividades como jogos e brincadeiras quase sempre são usadas como instrumento para regular, dirigir, controlar, ensinar, normatizar, punir, castigar, curar, educar [..."”.

Por esses motivos o ensino da Educação Física no contexto da Educação Infantil tem sido desafiado a compreender a criança como ser histórico, socialmente situado que possui diferentes necessidades e interesses (FREIRE, 2009). Nesse sentido, como pesquisador da área da Educação Física Escolar e como formador de professores, parto do princípio de que o 
objetivo da Educação Física, na Educação Infantil, é a alfabetização corporal da criança. A partir desse entendimento, o corpo passa a ser compreendido para além dos aspectos físicos, adentra a concepção de corpo como unidade, como conjunto atuante, falante, leitor e escritor e enfatiza a necessidade de uma visão educacional que desencadeia práticas educativas dos corpos. Mais especificamente uma "Pedagogia do Corpo Oprimido".

Os pressupostos epistemológicos dessa pedagogia compreendem as práticas corporais como manifestações culturais que devem possibilitar descobertas e ampliar as experiências corporais, culturais, sociais e educativas da criança. O educador, munido de tais pressupostos, reflete sobre o movimento corporal da criança de forma dinâmica e contextualizada, contribuindo para a formação de corpos conscientes.

Para isso, os professores de Educação Física necessitam compreender a escola como um espaço social que deve ser dissociado do mundo, da vida e da subjetividade da criança. Instituição social onde se deva estabelecer uma relação dialética criança/sociedade; em que o novo membro da sociedade, ao mesmo tempo em que é levado a compreender a regras e tratos sociais já existentes, deva ser orientado através do processo de socialização, de leitura de mundo, de dizer a sua palavra, de construir atitudes, opiniões, valores a respeito da sociedade mais ampla e; mais especificamente, do espaço de inserção de seu grupo social, a construindo seu corpo consciente por meio da alfabetização corporal. Alfabetização que deve respeitar as características de cada etapa do desenvolvimento da criança.

\section{A pedagogia do corpo oprimido como via para alfabetização corporal da criança}

Falar do corpo na Educação Física deveria ser uma tarefa simples, mas não é, apesar de ser um assunto bastante debatido e difundido nos cursos de formação acadêmica e produção científica da área; em virtude de ainda persistirem, no campo de atuação profissional, práticas educativas que interditam, negam e adestram corpos. Freire (1989) ao refletir sobre o lugar do corpo na educação conjecturou que a criança, ao entrar na escola, também deveria ter seu corpo matriculado, referindo-se ao processo de interdição do corpo que é realizado na medida em que alunos e alunas deixam de ser sujeitos de sua história, para tornarem-se objetos.

Postula Freire (1989, p. 157):

Não é possível que, em nome da educação, crianças e adolescentes sejam confinados em cubículos de meio metro quadrado, quatro horas por dia, cinco dias por semana, duzentos por ano, onze anos, num total de 8.800 horas de confinamento. É chocante, absurda, escandalosa essa educação sem corpo, essa deformação humana. 
Com esse tom de indignação, Freire (1989), na medida em que analisa a lógica do sistema educacional brasileiro, que tem a posse como centro e força motriz, denuncia o processo de interdição, coisificação, instrumentalização e dominação de corpos pelo sistema educativo.

Um sistema que, por meio de inúmeras técnicas disciplinares, nos afasta do nosso corpo, dos nossos sentidos, ao ponto de não sabermos mais quem somos, se temos um corpo ou se somos um corpo. Passamos por um processo de "descorporalização" - que perpassa a concepção de corpo máquina da modernidade, adentra a concepção de corpo sem corpo, de corpo invisível.

Essa escola que deixa marca no corpo não é a escola que Paulo Freire almejou. Paulo Freire foi desejoso de uma escola repleta de corpos conscientes, não só dos educandos, mas também dos educadores. Uma escola espiralada, que se movimenta de acordo com as necessidades de seus agentes, diferente daquela onde a criança fica sentada na cadeira, com seu corpo interditado e seu movimento corporal padronizado e fragmentado.

A Pedagogia do Oprimido, este ano (2020), comemora 52 anos de existência e tem levado educadores/as e educandos/a à reflexão acerca da denúncia/anúncio dos processos de desumanização e humanização. A problemática que cintila horizontes a essa proposta é: como desenvolver uma pedagogia do corpo oprimido que possibilite a alfabetização corporal da criança em consonância com a realidade social, levando em consideração o corpo como sujeito e os processos que devem transformá-lo em corpo consciente?

Em "Pedagogia do oprimido" escrita em (1968), no exílio, Freire apresenta um nítido manifesto pedagógico em favor corpo. Nesta obra, Freire compreende corpo como cultura e como caminho de libertação por meio da conscientização. Para ele: "quando se fala de oprimido, o corpo é o oprimido" (p. 45). Daí a necessidade de concebermos o corpo como educador, já que o corpo deve "corporificar a palavra pelo exemplo" (p. 38), que é exigência a todo educador. Por esse motivo, o que fazemos faz o nosso corpo. Daí, não podermos pensar sem ser, nem ser sem nosso corpo. Isso corresponde a dizer que, o corpo é hospedeiro do diálogo, que é próprio do corpo e se amplia e se ressignifica no encontro com o corpo do outro. De acordo com ele: "o outro que me vê, sou eu no outro. Essa relação não é só racional. Ela é, sobretudo, a extensão do próprio corpo" (p. 56).

Como se nota, a compreensão de corpo como sujeito, e como cultura encontra-se grafado no pensamento freiriano. Tal compreensão é oriunda da sua experiência social e de sua prática educativa como um "andarilho pelo mundo", e se movimenta na totalidade do seu pensamento em coerência e abertura dialogal; no intuito de possibilitar a compreensão das 
"razões de ser" e de "ler" o mundo, enquanto pressupostos, para exercitar a práxis de ampliar os horizontes de efetivação da liberdade subjetiva e intersubjetiva por meio de uma "Pedagogia do corpo oprimido". Pedagogia esta que traz um incômodo e cobre um vazio. O incômodo resiste na carga corporal que compõe essa pedagogia que adentra o campo da racionalidade não-corporal das instituições de ensino. Cobre o vazio do corpo porque rouba a atenção do corpo ao introduzir o político e consumar a educação para a cidadania dos esfarrapados, deixando a educação de ser transmissão de conteúdos herdados e desvinculados do mundo vivido pelos sujeitos para ser obra feita pelos e para os corpos oprimidos e sujeitados, os quais se tornarão 'temas geradores' no planejamento das ações institucionais e da prática educativa (FREIRE, 1968).

Nas esteiras do pensamento freiriano, a pedagogia do corpo possibilita a compreensão de que os indivíduos são consciência ativa de si e, assim, consciência do mundo, porque são um "corpo consciente". Para ele, na trama das relações sociais, homens e mulheres vivem uma relação dialética entre as privações e sua liberdade (FREIRE, 1968).

Diante de tais ponderações, sou inclinado a pensar que, no momento em que os sujeitos são alfabetizados corporalmente, eles são libertados. Tal qual dizia Freire (1968), não é libertação somente do sujeito, pois se o sujeito é compreendido como corpo, então também é a libertação do corpo, o corpo do sujeito, o corpo da pessoa.

Logo, um dos princípios da pedagogia do corpo oprimido é a indissociabilidade entre corpo/mente, consciência/corpo (PATRINHANI; AMÉRICO, 2020). Precisamos descobrir como a consciência perpassa a vivência do corpo da criança, fazendo a criança ter consciência de seus atos, levando-a a refletir sobre as práticas corporais que realiza. "Ah eu empurrei meu colega no parquinho", tenho três anos e empurrei, se eu vou para a sala da coordenação, o que eu perco nesse momento na aula prática? O professor munido dos princípios dessa pedagogia perceberá que esse é um bom momento para formação de corpos conscientes. Então, ele no Círculo de Cultura Corporal ${ }^{2}$ transformará aquele acontecimento em seu tema gerador.

Outro dia, fui acompanhar meus alunos do curso de licenciatura em Educação Física nas atividades de Estágio Supervisionado na Educação Infantil. Em meio a uma dinâmica que tomava as cantigas de roda como conteúdo da aula observei uma das crianças que, ao cantar as

${ }^{2}$ Conceito sistematizado pelo educador brasileiro Paulo Freire, os Círculos de Cultura estão fundamentados em uma proposta pedagógica, cujo caráter radicalmente democrático e libertador propõe uma aprendizagem integral, que rompe com a fragmentação e requer uma tomada de posição perante os problemas vivenciados em determinado contexto. Para Freire, essa concepção promove a horizontalidade na relação educador-educando e a valorização das culturas locais, da oralidade, contrapondo-se em seu caráter humanístico, à visão elitista de educação. Ver em: FREIRE, Paulo. Educação como prática de liberdade. 20. ed. Rio de Janeiro: Paz e Terra, 1987. 
cantigas, vibrava todo o seu corpo. Não sei se vocês já pararam para observar. Ninguém canta sem vivenciar o corpo. Como bem pontuam Damico e Knuth (2014, p. 331), “[...] a gente se expressa por meio do corpo e esse corpo fala, a gente não tem essa noção do corpo vivenciado, mas a gente se expressa por meio dele [...]”. Desse modo, quando proponho uma pedagogia do corpo oprimido para alfabetização corporal da criança, estou propondo aos educadores que, ao vivenciarem as práticas corporais em suas aulas, tomem o corpo da criança como método de ensino. Ao conceberem o corpo como método, estão disponibilizando aos alunos leques de possibilidades de leitura do mundo para, em seguida, apresentar a leitura da palavra.

Dito isso, é possível asseverar que, a Pedagogia do Corpo Oprimido contribui para que os seis direitos elencados na Base Nacional Comum Curricular (BNCC), sejam alcançados: 1. conviver, 2. brincar, 3. participar, 4. explorar, 5. expressar e 6. conhecer-se. A partir desses seis direitos, a BNCC estabeleceu também os campos de experiência, fundamentais para que a criança possa aprender e se desenvolver: $\mathrm{O}$ eu, o outro e o nós; Corpo, gestos e movimentos; Traços, sons, cores e formas; Escuta, fala, pensamento e imaginação; Espaços, tempos, quantidades, relações e transformações (BNCC, 2017).

As práticas corporais são, portanto, uma parte fundamental da aprendizagem e desenvolvimento da criança, via em que ela exercita todos os seus direitos e estabelece contato com os campos de experiência, como protagonista de seu desenvolvimento. Por isso, a importância de estruturação de uma pedagogia do corpo oprimido como meio para alfabetização corporal da criança. Pois, pelos seus pressupostos teóricos e metodológicos, os processos de ensino e aprendizagem devem ter por princípio a participação das crianças como protagonistas na busca pelo conhecimento e dos educadores como facilitadores e inspiradores dessa busca.

Nas esteiras da pedagogia do corpo oprimido a criança é compreendida e respeitada como ser único que desenvolve seu aprendizado e é sempre capaz de encontrar a melhor maneira para construir seus conhecimentos, respeitando a heterogeneidade e a individualidade da comunidade escolar.

Além disso, propõe o compartilhamento das decisões entre alunos e professores. Tratase de uma pedagogia que propõe a construção de uma educação corporal para todos, buscando sempre a melhoria na qualidade do ensino.

Nesse sentido, pedagogia do corpo oprimido, de diversas formas, em diferentes espaços e tempos e com diferentes pares, torna-se um caminho possível de ampliar e diversificar o universo corporal infantil, criando novas possibilidades de compreensão corporal, de seus limites e possibilidades. 


\section{Considerações finais}

Como argumentei até aqui, tomar os princípios teóricos e metodológicos da Pedagogia do Corpo Oprimido, como via para alfabetização corporal da criança, é conceber uma educação corporal como um caminho que oportuniza a criança a criar, recriar-se, descobrir-se, redescobrir-se, fazer-se, refazer-se, na medida em que vai se desvelando, lendo-se e lendo o mundo, manifestando-se e configurando-se como corpo consciente.

Logo, requer do educador a ampliação do entendimento do conceito de criança, corpo e práticas corporais. Não se admite a concepção de corpo como objeto, muito menos de consciência como algo localizado, como se fosse uma parte da criança, cirurgicamente fragmentada; uma espécie de corpo-consciência.

Nesse sentido, o educador freirianamente situado conceberá a criança como um ser no mundo, que habita o mundo, com o mundo e com os outros; como ser concretamente situado que encontra-se num processo de mútua construção e reconstrução. Um ser consciente de sua prática, de sua existência vivenciada por meio de sua corporeidade.

Como ser da práxis, a criança se alfabetiza corporalmente por meio das experiências as quais lhe são oferecidas, da apresentação e problematização de novas realidades, de novos movimentos capazes de produzir ineditismos, fazendo com que tome consciência de seu corpo, de sua presença e interferência no mundo. Nas esteiras do pensamento freiriano, os sujeitos decifram-se a si mesmos como sujeitos e leem em seus corpos, e nos corpos dos outros, sua e vossa humanidade, à medida que se percebem mais conscientes de suas disposições.

Contudo, finalizo este estudo, alertando os meus pares sobre a não existência de um modelo para seguir nessa concepção educativa. O que existe é uma teoria do conhecimento que proporciona aos educadores alguns pressupostos que deverão ser recriados para que sejam adequados ao contexto social e educacional em que serão utilizados. Significa dizer, que ser coerente com a proposta educacional freiriana exige a sua reinvenção, requer análise constante das ações pedagógicas e metodologias de ensino ativas, inventivas e empoderadoras, pensadas a partir das experiências corporais, sociais, culturais e materiais vivenciadas pela criança.

\section{REFERÊNCIAS}

AWAD, H. Educação física escolar: múltiplos caminhos. São Paulo: Fontoura, 2010.

AYOUB, E. Reflexões sobre educação física na educação infantil. Revista Paulista de Educação Física, São Paulo, supl. 4, p. 53-60, 2001. 
BASEI, A. P. A Educação física na educação infantil: a importância do movimentar-se e suas contribuições no desenvolvimento da criança. Revista Iberoamericana de Educación, v. 3. n. 47, p. 1-12, 2008.

BETTI, M. Educação física e sociedade. São Paulo: Movimento, 1991.

BRASIL. Lei n. 9.394, de 20 de dezembro de 1996. Estabelece as diretrizes e bases da Educação Nacional. Diário Oficial da União: Seção 1, Brasília, DF: MEC, p. 27833, 23 dez. 1996. PL 1258/1988

BRASIL, Ministério da Educação. Secretária de Educação Fundamental. Parâmetros Curriculares Nacionais: Educação Física $\left(1^{\circ}\right.$ e $2^{\circ}$ ciclos do ensino fundamental). Brasília: MEC, 1997. v. 7.

BRASIL. Ministério da Educação. Secretaria da Educação Básica. Fundamentos pedagógicos e estrutura geral da BNCC. Brasília, DF, 2017.

BROTTO, F. O. Jogos cooperativos: se o importante é competir, o fundamental é cooperar. São Paulo: Cepeusp, 1995.

COLETIVO DE AUTORES. Metodologia do ensino da educação física. São Paulo: Cortez, 1992.

CORREIA, M. S. Empowerment de professores e alunos por meio da pedagogia do esporte. Periferia, v. 12, n. 1, p. 280-299, jan./abr. 2020.

CORREIA, M. S.; MARQUES, B. G.; MIRANDA, M. L. J. A educação física escolar ancorada na gênese ideológica de Paulo Freire: um caminho para conscientização dos esfarrapados e esfarrapadas do mundo. In: SOUSA, C. A.; NOGUEIRA, V. A.;

MALDONADO, D. T. (Org.). Educação física escolar e Paulo Freire: ações e reflexões em tempos de chumbo. Curitiba, PR: Editora CRV, 2019. p. 33-50.

CORREIA, M. S.; MIRANDA, M. L. J.; VELARDI, M. A prática da educação física para idosos ancorada na pedagogia freireana: reflexões sobre uma experiência dialógica problematizadora. Movimento, Porto Alegre, v. 17, n. 4, p. 281-297, 2011.

DAMICO, J.; KNUTH, A. O des(encontro) das práticas corporais e atividade física: Hibridizações e borramentos no campo da saúde. Movimento, Porto Alegre, v. 20, n. 1, p. 329-350, jan./mar. 2014.

DAOLIO, J. Os significados do corpo e as implicações para a Educação Física. Movimento, v. 2, n. 2, p. 24-28, 1995.

FREIRE, J. B. Educação de corpo inteiro: teoria e prática da educação. Paulo: Scipione, 2011. (Coleção Pensamento e ação na sala de aula)

FREIRE, P. Pedagogia do oprimido. Rio de Janeiro: Paz e Terra, 1968.

FREIRE, P. Educação como prática de liberdade. Rio de Janeiro: Paz e Terra, 1987. 
FREIRE, P. A importância do ato de ler: em três artigos que se complementam. 23.ed. São Paulo. Autores associados: Cortez, 1989.

FREIRE, P. Pedagogia da Esperança: um reencontro com a Pedagogia do Oprimido. 16. ed. Rio de Janeiro: Paz e Terra, 2009.

TANI, G. Abordagem desenvolvimentista: 20 anos depois. Ver. Educ. Fís., Maringá, v. 19, n. 3, p. 33-41, 2008.

KUNZ, E. Educação física: ensino e mudança. Ijuí: Unijuí, 1991.

KUNZ, E. Transformação didático-pedagógica do esporte. Ijuí: Unijuí, 1994.

LE BOULCH, J. Educação psicomotora: a psicomotricidade na idade escolar. Porto Alegre: Artes Médicas, 1981.

MOREIRA, E. C. Educação física escolar: desafios e propostas 1. São Paulo: Fontoura, 2009.

MOREIRA, E. C.; NISTA-PICCOLO, V. L. (Org.). O quê e como ensinar educação física na escola. Jundiaí: Fontoura, 2009.

MOREIRA, E. C.; PEREIRA, R. Educação física escolar: desafios e propostas 2 - Várzea Paulista. São Paulo: Fontoura, 2011.

NEIRA, M. G. A reflexão e a prática no ensino da educação física. São Paulo: Blucher, 2001. v. 8. (Coleção a reflexão e a prática no ensino)

NISTA-PICCOLO, V. L.; MOREIRA, W. W. Esporte como conhecimento e prática nos anos iniciais do Ensino Fundamental. São Paulo: Cortez, 2012.

PATRINHANI, G. F.; AMÉRICO, M. Mídia, Cultura de Paz e Educação Física Escolar. RIAEE - Revista Ibero-Americana de Estudos em Educação, Araraquara, v, 15, n. 4, p. 1991-2005, 2020.

RESENDE, M. S. Creche: crianças, faz-de-conta \& Cia. Petrópolis: Vozes, 2015.

SAYÃO, D. T. Infancia, prática de ensino de Educação Física e Educação Infantil. In: VAZ, A. F.; SAYÃO, D. T.; PINTO, F. M. (Org.): Educação do corpo e formação de professores: reflexões sobre a prática de ensino de educação física. Florianópolis: UFSC, 2002.

SAYÃO, D. T. Educação física na educação infantil: riscos, conflitos e controvérsias. Motrivivência, v. 11, n. 13, p. 21-38,1999.

SILVA, I. M. P. A.; CORREIA, M. S. Discriminação nas aulas de educação física: memórias de uma aluna trans. FIEP BULLETIN, v. 90, n. 1, p. 265-267, Edição Especial, 2020. 


\section{Como referenciar este artigo}

CORREIA, M. S. A pedagogia do corpo oprimido como via para alfabetização corporal da criança. Revista on line de Política e Gestão Educacional, Araraquara, v. 24, n. 3, p. 15591572, set./dez. 2020. e-ISSN:1519-9029. DOI: https://doi.org/10.22633/rpge.v24i3.14170

Submetido em: 30/06/2020

Revisões requeridas: $31 / 07 / 2020$

Aprovado em: 28/08/2020

Publicado em: 01/09/2020 